Arq. Bras. Med. Vet. Zootec., v.65, n.3, p.783-791, 2013

\title{
Lesões melanocíticas em suínos abatidos para consumo
}

\author{
[Melanocytic lesions in pigs slaughtered for consumption] \\ C. Teixeira, I. Pires, S. Ferreira, M. Vieira-Pinto* \\ Universidade de Trás-os-Montes e Alto Douro (UTAD) - Centro de Ciência Animal e \\ Veterinária (CECAV) - Vila Real Codex, Portugal \\ RESUMO
}

\begin{abstract}
O presente estudo teve como principais objetivos conhecer a taxa de ocorrência de lesões melanocíticas (melanose, melanocitomas e melanomas) em suínos abatidos para consumo e identificar possíveis padrões de distinção e de classificação macroscópica dessas lesões. Para tal, procedeu-se à recolha de lesões melanocíticas em matadouro, durante oito meses, e à sua avaliação macroscópica e microscópica. Os resultados deste estudo demonstraram que as melanoses foram as lesões melanocíticas mais frequentemente encontradas $(74,04 \%)$ e que, relativamente às lesões tumorais, os melanomas (malignos) foram os mais frequentes $(21,15 \%)$ comparativamente com os melanocitomas (benignos) $(4,81 \%)$. Pela análise comparativa das características macroscópicas e microscópicas, verificou-se que, nem sempre, por uma avaliação macroscópica, é possível a distinção entre essas lesões (melanoses, melanocitomas e melanomas). No entanto, identificaram-se, neste estudo, algumas características sugestivas da malignidade, como: o tamanho superior a $2,5 \mathrm{~cm}$, a presença de ulceração, a libertação de pigmento negro e a presença de coloração negra do gânglio linfático regional. É, portanto, de extrema importância a observação criteriosa e sistemática dessas lesões, para a avaliação das suas características, uma vez que a decisão sanitária é diferente consoante se trate de uma melanose, de um tumor maligno ou de um tumor benigno.
\end{abstract}

Palavras-chave: suínos, melanose, melanocitoma, melanoma, abatedouro

\begin{abstract}
The main objective of the present study was to know the rate of occurrence of melanocytic lesions (melanosis, melanocytoma and melanoma) in pigs slaughtered for consumption and to identify possible patterns of differentiation and a macroscopic classification of these lesions. To this end, we proceeded to the collection of melanocytic lesions in a slaughterhouse during 8 months, and its macroscopic and microscopic evaluation. The results of this study demonstrated that melanosis were the most often found melanocytic lesions (74.04\%) and that for tumors, melanomas (malignant) were the most frequent $(21.15 \%)$ compared to melanocytomas (benign) (4.81\%). By comparative analysis of macroscopic and microscopic characteristics we found that it is not always possible, with a macroscopic evaluation, to distinguish between these lesions (melanosis, melanocytoma and melanoma). However, in this study we identified some features suggestive of malignancy such as: size exceeding $2.5 \mathrm{~cm}$, the presence of ulceration, the release of black pigment and the presence of a black staining of the regional lymph node. Therefore, it is extremely important to make a careful and systematic observation of these lesions, with the evaluation of their characteristics, since the sanitary decision is different if they are melanosis, malignant tumors or benign tumors.
\end{abstract}

Keywords: pigs, melanosis, melanocytoma, melanoma, slaugtherhouse

Recebido em 25 de julho de 2011

Aceito em 11 de janeiro de 2013

*Autor para correspondência (corresponding author)

E-mail: mmvpinto@utad.pt 


\section{INTRODUÇÃO}

De acordo com Bundza e Felmate (1990), as lesões melanocíticas (melanose, melanocitomas e melanomas) podem ser encontradas em suínos abatidos para consumo, sendo necessário distinguir a melanose (pigmentação não neoplásica) dos tumores melanocíticos e, no caso de se tratar de um tumor, se este é benigno (melanocitoma) ou maligno (melanoma), para proceder a uma adequada decisão sanitária da carcaça e das respectivas vísceras. Até a presente data, os dados sobre a ocorrência dessas lesões nos animais de produção são raros (Ramos et al., 2008).

A melanose ocorre quando há um armazenamento anormal de melanina, com acumulação desse pigmento nos tecidos. Caracteriza-se pela presença de uma pigmentação negra, castanha ou cinzenta, nos tecidos ou órgãos, sem alteração da estrutura deles (Jones e Hunt, 1983). Pode apresentar uma etiologia congênita nas raças Sinclair, Duroc, Hormel e Vietnamita (Bundza e Felmate, 1990) ou ser adquirida, como é o caso da melanose resultante de uma alimentação à base de bolota (Lanteri et al., 2009).

Os tumores melanocíticos apresentam uma etiologia multifatorial (radiação solar, vírus, agentes químicos) (Baba, 2007), no entanto o fator hereditário está presente nas raças Sinclair, Duroc, Hormel, Hampshire e Ibérica (Hordinsky et al., 1985; Tissot et al., 1987; Scott, 2007). Aparecem como formações planas, elevadas ou nodulares, de cor negra, castanha ou cinzenta, e que podem variar entre os 0,3 e os $25 \mathrm{~cm}$ de diâmetro (Scott, 2007). Os melanocitomas são bem localizados (Stannard e Pulley, 1978; Pestana, 1995; Goldschmidt e Hendrick, 2002; Withrow e Vail, 2007) e os melanomas apresentam um crescimento infiltrativo e podem até ser ulcerados (Smith et al., 2002).

No decurso da inspeção sanitária, é, muitas vezes, impossível identificar a natureza neoplásica das lesões ou determinar a sua malignidade, no caso dos tumores melanocíticos (Becker et al., 2006). Para isso, é necessário recorrer a exames histopatológicos, o que nem sempre é possível. Porém, o diagnóstico da lesão é de extrema importância, já que as diferentes lesões se refletem em diferentes decisões sanitárias. Portanto, há necessidade de se definirem possíveis parâmetros lesionais, observáveis no matadouro, que possam ser indicativos de agressividade tumoral e possam, assim, sustentar uma decisão sanitária.

A legislação europeia que estabelece as regras específicas de organização dos controles oficiais de produtos de origem animal destinados ao consumo humano não prevê nenhum critério de decisão sanitária específico para essas lesões, referindo apenas que, sempre que ocorram alterações fisiopatológicas, as carnes devem ser declaradas impróprias para consumo (Regulamento 854/2004). Segundo as recomendações expressas no Codex Alimentarius (FAO/OMS, 1994), deve-se proceder a uma reprovação parcial da carcaça ou das vísceras afetadas pela presença de uma melanose localizada ou de um tumor benigno, único e circunscrito, e a uma reprovação total na presença de uma melanose generalizada e na presença de tumores malignos ou múltiplos.

Pelo exposto, considera-se importante ampliar o nível de conhecimento sobre a ocorrência e a caracterização das lesões melanocíticas em suínos ao abate. Assim, o presente trabalho teve como principais objetivos a contribuição para o estudo dessas lesões em suínos abatidos para consumo e a identificação das características macroscópicas que permitissem a distinção da melanose dos tumores melanocíticos e, nestes, a distinção entre melanocitoma e melanoma, fatores que se revestem de grande interesse para a atribuição de critérios de decisão sanitária mais corretos, sólidos e eficazes, no âmbito da inspeção higiênico-sanitária de suínos.

\section{MATERIAL E MÉTODOS}

Durante oito meses (de setembro de 2009 a abril de 2010), foram recolhidas amostras $(n=104)$ de lesões melanocíticas e do respectivo gânglio linfático regional em suínos abatidos para consumo em diversos matadouros de Portugal. Após a colheita da amostra no matadouro, foi efetuado o registo das características macroscópicas das lesões, tendo sido utilizada a seguinte classificação: tipo 1 (lesão plana, não ulcerada); tipo 2 (lesão plana, ulcerada); tipo 3 (lesão elevada, não ulcerada); tipo 4 (lesão elevada, ulcerada). A caracterização dos tumores também englobou a avaliação de características 
sugeridas por Ramos-Vara et al., 2000; Pérez et al., 2002: o tamanho $(<0,5 \mathrm{~cm} ; 0,5-2,5 \mathrm{~cm} ; 2,6-$ $5 \mathrm{~cm}$; 5,1-10cm; $>10 \mathrm{~cm}$ ); a forma (plana ou elevada); as bordas (regulares ou irregulares); a superfície (lisa ou rugosa); a libertação de pigmento (presente ou ausente); a ulceração (presente ou ausente); a consistência (firme ou branda). Posteriormente, as amostras foram colocadas em frascos rotulados, com formol tamponado a $10 \% \quad(\mathrm{pH} 7,0 \pm 0.2)$. Todas as amostras foram encaminhadas para o Laboratório de Histologia e Anatomia Patológica da UTAD, em menos de 24 horas.

No Laboratório de Histologia e Anatomia Patológica da UTAD, o material foi incluído em parafina e efetuaram-se cortes seriados $(2-3 \mu \mathrm{m})$ Um desses cortes foi corado com hematoxilinaeosina (HE) (Pérez et al., 2002; Pires et al., 2004) e o outro sofreu tratamentos de branqueamento segundo o método proposto por Pearse (1972), citado por Carleton et al. (1980). As lesões foram classificadas em melanose e, de acordo com a Classificação Histológica de Tumores de Pele nos Animais Domésticos proposta pela Organização Mundial de Saúde (OMS), em melanocitomas e melanomas (Goldschmidt et al., 1998).

A caracterização microscópica das lesões tumorais englobou características descritas por (Ramos-Vara et al., 2000; Millanta et al. 2002; Spangler e Kass, 2006): o tipo celular (epitelioide, fusiforme, misto); a localização (epiderme, derme, hipoderme); a atividade juncional (presente ou ausente); a atipia citonuclear (grau 1 (fraco), grau 2 (moderado), grau 3 (severo)); a proliferação intraepitelial (presente ou ausente); a ulceração (presente ou ausente); o grau de pigmentação (de acordo com uma escala subjetiva: grau 0 (ausente), grau 1 (leve - 0 a $30 \%$ de células com pigmento melânico), grau 2 (moderado - 31\% a 80\%), grau 3 (severo - mais de $81 \%$ )); a organização perivascular (presente ou ausente); as células tumorais intravasculares (CTI) (presentes ou ausentes).

\section{RESULTADOS E DISCUSSÃO}

Das 104 lesões melanocíticas recolhidas, 77 eram melanoses $(74,04 \%)$, cinco eram melanocitomas $(4,81 \%)$ e 22 eram melanomas $(21,15 \%)$. Os resultados encontrados neste estudo no que diz respeito às lesões melanocíticas não estão de acordo com o descrito por Scott (2007), o qual se refere ao fato de que a maioria das neoplasmas melanocíticas encontradas em suínos são melanocitomas. No entanto, essa comparação deve ser interpretada de uma forma cautelosa, uma vez que o autor não faz referência à metodologia nem aos critérios de diagnóstico utilizados e apenas se refere às raças consideradas por ele como predispostas (Duroc, Sinclair, Hormel, Hampshire e Ibérico), as quais não foram contempladas neste estudo.

Na Tab. 1, encontra-se referida a localização do conjunto de amostras analisadas por animal.

Tabela 1. Localização e diagnóstico histopatológico do conjunto de amostras analisadas por animal

\begin{tabular}{|c|c|c|c|c|c|c|c|c|}
\hline \multirow{2}{*}{\multicolumn{3}{|c|}{ Suínos analisados }} & \multicolumn{6}{|c|}{ Diagnóstico } \\
\hline & & & \multicolumn{2}{|c|}{ Melanoses } & \multicolumn{2}{|c|}{ Melanocitomas } & \multicolumn{2}{|c|}{ Melanomas } \\
\hline Órgão(s) afetado(s) & $\mathrm{n}$ & $\%$ & $\mathrm{n}$ & $\%$ & $\mathrm{~N}$ & $\%$ & $\mathrm{n}$ & $\%$ \\
\hline G. mamária & 46 & 44,23 & 46 & 59,74 & 0 & 0 & 0 & 0 \\
\hline Pulmão & 22 & 21,15 & 22 & 28,57 & 0 & 0 & 0 & 0 \\
\hline Pele & 19 & 18,27 & 1 & 1,30 & 5 & 100 & 13 & 59,09 \\
\hline G. mamária + timo & 1 & 0,96 & 1 & 1,30 & 0 & 0 & 0 & 0 \\
\hline G. mamária + g. salivar & 1 & 0,96 & 1 & 1,30 & 0 & 0 & 0 & 0 \\
\hline Pele + gânglio linfático & 9 & 8,65 & 2 & 2,60 & 0 & 0 & 7 & 31,82 \\
\hline Fígado + pulmão & 1 & 0,96 & 1 & 1,30 & 0 & 0 & 0 & 0 \\
\hline G. mamária + pulmão & 3 & 2,88 & 3 & 3,90 & 0 & 0 & 0 & 0 \\
\hline Pele + gânglio linfático + pulmão & 1 & 0,96 & 0 & 0 & 0 & 0 & 1 & 4,55 \\
\hline Mais de três órgãos & 1 & 0,96 & 0 & 0 & 0 & 0 & 1 & 4,55 \\
\hline Total & 104 & 100 & 77 & - & 5 & - & 22 & - \\
\hline
\end{tabular}


Pela análise da Tab. 1, pode-se verificar que a melanose apareceu majoritariamente na glândula mamária, como lesão única $(n=46 ; 59,74 \%)$ ou múltipla associada à presença em outros órgãos, como o timo, a glândula salivar e o pulmão. Depois da glândula mamária, o pulmão $(n=22$; $28,57 \%$ ) foi o órgão que evidenciou maior ocorrência de melanose. Os locais de aparecimento da melanose coincidiram com os encontrados por outros autores, como Jones e Hunt (1983), Pestana (1995), Herenda et al. (2000), Lanteri et al. (2009) e Jin et al. (2009).

Segundo Oxenhandler e Hook (1979), Vargas (2005), Baba (2007), Ginn et al. (2007) e Camargo et al. (2008), os melanócitos podem migrar durante a embriogênese para a epiderme, derme, entre outros locais, de modo que os tumores melanocíticos possam ocorrer em outros locais que não a pele. No presente estudo e quanto às lesões tumorais, os melanocitomas (benignos) surgiram todos na pele como lesão única $(\mathrm{n}=5 ; 100,00 \%)$, contrariamente aos melanomas (malignos), dos quais apenas cerca de metade surgiu como lesão única na pele $(\mathrm{n}=13 ;$ 59,09\%). Dos restantes melanomas identificados, $31,82 \%(n=7)$ foram encontrados na pele e no seu gânglio linfático regional.

$\mathrm{Na}$ Tab. 2, encontra-se referido o tipo de lesão e o diagnóstico histopatológico associados ao conjunto de amostras analisadas por animal.

Tabela 2. Tipo de lesão e diagnóstico histopatológico do conjunto de amostras analisadas por animal

\begin{tabular}{|c|c|c|c|c|c|c|c|c|c|c|c|c|c|c|c|c|c|c|c|c|c|c|}
\hline \multirow[t]{2}{*}{ Diagnóstico } & \multirow[t]{2}{*}{ 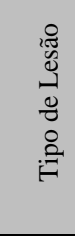 } & \multicolumn{2}{|c|}{ 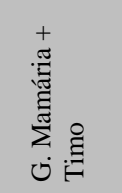 } & \multicolumn{2}{|c|}{ 莺 } & \multicolumn{2}{|c|}{ 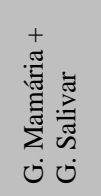 } & \multicolumn{2}{|c|}{ 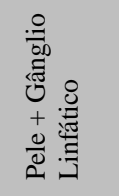 } & \multicolumn{2}{|r|}{$\frac{0}{0}$} & \multicolumn{2}{|c|}{ 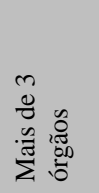 } & \multicolumn{2}{|c|}{ 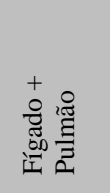 } & \multicolumn{2}{|c|}{ 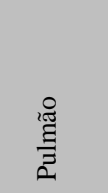 } & \multicolumn{2}{|c|}{ 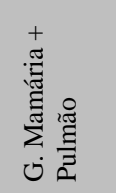 } & \multicolumn{2}{|c|}{ 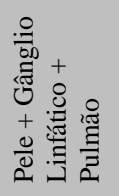 } & \multirow[t]{2}{*}{ స్త్ర } \\
\hline & & $\mathrm{n}$ & $\%$ & $\mathrm{n}$ & $\%$ & $\mathrm{n}$ & $\%$ & $\mathrm{n}$ & $\%$ & $\mathrm{n}$ & $\%$ & $\mathrm{n}$ & $\%$ & $\mathrm{n}$ & $\%$ & $\mathrm{n}$ & $\%$ & $\mathrm{n}$ & $\%$ & $\mathrm{n}$ & $\%$ & \\
\hline \multirow{5}{*}{ Melanose } & $\begin{array}{c}\text { Tipo } \\
1\end{array}$ & 1 & 100 & 46 & 100 & 1 & 100 & 2 & 22,22 & 1 & 5,26 & 0 & 0 & 1 & 100 & 22 & 100 & 3 & 100 & 0 & 0 & 77 \\
\hline & $\begin{array}{c}\text { Tipo } \\
2\end{array}$ & 0 & 0 & 0 & 0 & 0 & 0 & 0 & 0 & 0 & 0 & 0 & 0 & 0 & 0 & 0 & 0 & 0 & 0 & 0 & 0 & 0 \\
\hline & $\begin{array}{c}\text { Tipo } \\
3\end{array}$ & 0 & 0 & 0 & 0 & 0 & 0 & 0 & 0 & 0 & 0 & 0 & 0 & 0 & 0 & 0 & 0 & 0 & 0 & 0 & 0 & 0 \\
\hline & $\begin{array}{c}\text { Tipo } \\
4\end{array}$ & 0 & 0 & 0 & 0 & 0 & 0 & 0 & 0 & 0 & 0 & 0 & 0 & 0 & 0 & 0 & 0 & 0 & 0 & 0 & 0 & 0 \\
\hline & $\begin{array}{c}\text { Tipo } \\
1\end{array}$ & 0 & 0 & 0 & 0 & 0 & 0 & 0 & 0 & 5 & 26,32 & 0 & 0 & 0 & 0 & 0 & 0 & 0 & 0 & 0 & 0 & 5 \\
\hline \multirow{3}{*}{ Melanocitoma } & $\begin{array}{c}\text { Tipo } \\
2\end{array}$ & 0 & 0 & 0 & 0 & 0 & 0 & 0 & 0 & 0 & 0 & 0 & 0 & 0 & 0 & 0 & 0 & 0 & 0 & 0 & 0 & 0 \\
\hline & $\begin{array}{c}\text { Tipo } \\
3\end{array}$ & 0 & 0 & 0 & 0 & 0 & 0 & 0 & 0 & 0 & 0 & 0 & 0 & 0 & 0 & 0 & 0 & 0 & 0 & 0 & 0 & 0 \\
\hline & $\begin{array}{c}\text { Tipo } \\
4\end{array}$ & 0 & 0 & 0 & 0 & 0 & 0 & 0 & 0 & 0 & 0 & 0 & 0 & 0 & 0 & 0 & 0 & 0 & 0 & 0 & 0 & 0 \\
\hline \multirow{4}{*}{ Melanoma } & $\begin{array}{c}\text { Tipo } \\
1\end{array}$ & 0 & 0 & 0 & 0 & 0 & 0 & 0 & 0 & 3 & 15,79 & 0 & 0 & 0 & 0 & 0 & 0 & 0 & 0 & 0 & 0 & 3 \\
\hline & $\begin{array}{c}\text { Tipo } \\
2\end{array}$ & 0 & 0 & 0 & 0 & 0 & 0 & 1 & 11,11 & 8 & 42,11 & 0 & 0 & 0 & 0 & 0 & 0 & 0 & 0 & 1 & 100 & 10 \\
\hline & $\begin{array}{c}\text { Tipo } \\
3\end{array}$ & 0 & 0 & 0 & 0 & 0 & 0 & 0 & 0 & 0 & 0 & 0 & 0 & 0 & 0 & 0 & 0 & 0 & 0 & 0 & 0 & 0 \\
\hline & $\begin{array}{c}\text { Tipo } \\
4\end{array}$ & 0 & 0 & 0 & 0 & 0 & 0 & 6 & 66,67 & 2 & 10,53 & 1 & 100 & 0 & 0 & 0 & 0 & 0 & 0 & 0 & 0 & 9 \\
\hline Total & & 1 & - & 46 & - & 1 & - & 9 & - & 19 & - & 1 & - & 1 & - & 22 & - & 3 & - & 1 & - & 104 \\
\hline
\end{tabular}

G - glândula; tipo 0 = lesões de cor cinzenta; tipo 1 = lesão plana, não ulcerada; tipo 2 = lesão plana, ulcerada; tipo 3 = lesão elevada, não ulcerada; tipo 4 = lesão elevada, ulcerada.

A melanose resulta de uma deposição de melanina em vários órgãos, especialmente nos pulmões, originando manchas cinzentas, negras ou acastanhadas, de contornos irregulares, com alguns centímetros de diâmetro (Jones e Hunt, 1983). As lesões de melanose encontradas neste estudo caracterizaram-se por uma coloração cinzenta a negra, com disposição focal, multifocal ou multifocal coalescente, planas, circunscritas, não ulceradas, sem aparente envolvimento dos tecidos adjacentes e majoritariamente do tipo $1(\mathrm{n}=77,100 \%)$, sendo 
macroscopicamente semelhantes aos cinco casos de melanocitomas, mas diferentes dos melanomas. Por sua vez, os melanocitomas apresentaram-se como lesões do tipo $1 \quad(n=5$; $100 \%$ ). Esse dado está de acordo com os autores Stannard e Pulley (1978), que indicam, adicionalmente, que essas lesões tumorais benignas são, em sua maioria, máculas planas. Os melanomas podem apresentar várias formas, desde máculas planas a nódulos (Sobestiansky e Barcellos, 2000); os maiores podem até ser ulcerados (Smith et al., 2002). No presente estudo, os melanomas mostraram-se do tipo 2 $(\mathrm{n}=10 ; 45,45 \%)$ ou $4 \quad(\mathrm{n}=9 ; 40,91 \%)$. As características macroscópicas dos melanocitomas e dos melanomas identificados neste estudo encontram-se na Tab. 3 .

Tabela 3. Caracterização macroscópica dos melanocitomas e melanomas

\begin{tabular}{|c|c|c|c|c|c|}
\hline \multirow{2}{*}{\multicolumn{2}{|c|}{ Caracterização macroscópica }} & \multicolumn{2}{|c|}{ Melanocitomas $(n=5)$} & \multicolumn{2}{|c|}{ Melanomas $(n=22)$} \\
\hline & & $\mathrm{n}$ & $\%$ & $\mathrm{n}$ & $\%$ \\
\hline \multirow{5}{*}{ Tamanho (cm) } & $<0,5$ & 0 & 0 & 2 & 9,09 \\
\hline & $0,5-2,5$ & 5 & 100 & 12 & 54,55 \\
\hline & $2,6-5,0$ & 0 & 0 & 6 & 27,27 \\
\hline & $5,1-10,0$ & 0 & 0 & 2 & 9,09 \\
\hline & $>10,0$ & 0 & 0 & 0 & 0 \\
\hline \multirow{2}{*}{ Forma } & Plana & 5 & 100 & 12 & 54,55 \\
\hline & Elevada & 0 & 0 & 10 & 45,45 \\
\hline \multirow{2}{*}{ Bordas } & Regulares & 2 & 40 & 4 & 18,18 \\
\hline & Irregulares & 3 & 60 & 18 & 81,82 \\
\hline \multirow{2}{*}{ Superfície } & Lisa & 5 & 100 & 5 & 22,73 \\
\hline & Rugosa & 0 & 0 & 17 & 77,27 \\
\hline \multirow{2}{*}{$\begin{array}{l}\text { Libertação de } \\
\text { pigmento }\end{array}$} & Presente & 0 & 0 & 12 & 54,55 \\
\hline & Ausente & 5 & 100 & 10 & 45,45 \\
\hline \multirow{2}{*}{ Ulceração } & Presente & 0 & 0 & 19 & 86,36 \\
\hline & Ausente & 5 & 100 & 3 & 13,64 \\
\hline \multirow{2}{*}{ Consistência } & Firme & 0 & 0 & 11 & 50,00 \\
\hline & Branda & 5 & 100 & 11 & 50,00 \\
\hline
\end{tabular}

As neoplasmas melanocíticas podem apresentar características macroscópicas muito variáveis (Scott, 2007). Neste estudo, os melanocitomas caracterizaram-se por serem planos, não encapsulados, circunscritos, de superfície lisa e sem liberação de pigmento ou ulceração. Por sua vez, os melanomas caracterizaram-se por serem lesões geralmente planas, de superfície rugosa e ulcerada e com liberação de pigmento. Essas características são consistentes com diversos estudos, como os de Sobestiansky e Barcellos (2000), Goldschmidt e Hendrick (2002) e Smith et al. (2002) e Scott (2007). Assim, dadas as características macroscópicas encontradas nas lesões avaliadas, sugerem-se como possíveis indicadores de malignidade (melanoma) as seguintes lesões, sobretudo quando associadas: a forma elevada; a superfície rugosa; a ulceração; a liberação de pigmento.

Microscopicamente, as lesões de melanose evidenciavam uma acumulação de pigmento negro em melanócitos no tecido conjuntivo e no citoplasma das células epiteliais. Essa acumulação não leva à alteração estrutural dos tecidos, como nos indicam Jones e Hunt (1983).

As características microscópicas do melanocitoma e do melanoma encontram-se listadas na Tab. 4. 
Teixeira et al.

Tabela 4. Caracterização microscópica dos melanocitomas e melanomas

\begin{tabular}{|c|c|c|c|c|c|}
\hline \multirow{2}{*}{\multicolumn{2}{|c|}{ Caracterização microscópica }} & \multicolumn{2}{|c|}{ Melanocitomas $(n=5)$} & \multicolumn{2}{|c|}{ Melanomas $(n=22)$} \\
\hline & & $\mathrm{n}$ & $\%$ & $\mathrm{n}$ & $\%$ \\
\hline \multirow{3}{*}{ Tipo celular } & Epitelioide & 5 & 100 & 15 & 68,18 \\
\hline & Fusiforme & 0 & 0 & 4 & 18,18 \\
\hline & Misto & 0 & 0 & 3 & 13,64 \\
\hline \multirow{3}{*}{ Localização } & Epiderme + derme & 0 & 0 & 5 & 22,73 \\
\hline & Epiderme+derme+hipoderme & 0 & 0 & 16 & 72,72 \\
\hline & Derme & 5 & 100 & 1 & 4,55 \\
\hline \multirow{2}{*}{$\begin{array}{l}\text { Crescimento } \\
\text { infiltrativo }\end{array}$} & Presente & 0 & 0 & 22 & 100 \\
\hline & Ausente & 5 & 100 & 0 & 0 \\
\hline \multirow{2}{*}{ Atividade juncional } & Presente & 0 & 0 & 22 & 100 \\
\hline & Ausente & 5 & 100 & 0 & 0 \\
\hline \multirow{3}{*}{$\begin{array}{l}\text { Grau de atipia } \\
\text { citonuclear }\end{array}$} & Grau 1 (fraco) & 5 & 100 & 0 & 0 \\
\hline & Grau 2 (moderado) & 0 & 0 & 7 & 31,82 \\
\hline & Grau 3 (severo) & 0 & 0 & 15 & 68,18 \\
\hline \multirow{3}{*}{$\begin{array}{l}\text { Proliferação } \\
\text { intraepitelial }\end{array}$} & Presente & 0 & 0 & 18 & 81,82 \\
\hline & Ausente & 5 & 100 & 4 & 18,18 \\
\hline & Grau 0 (ausente) & 0 & 0 & 0 & 0 \\
\hline \multirow{3}{*}{$\begin{array}{l}\text { Grau de } \\
\text { pigmentação }\end{array}$} & Grau 1 (leve) & 0 & 0 & 0 & 0 \\
\hline & Grau 2 (moderado) & 5 & 100 & 5 & 22,73 \\
\hline & Grau 3 (severo) & 0 & 0 & 17 & 77,27 \\
\hline \multirow{4}{*}{$\begin{array}{l}\text { Organização } \\
\text { perivascular } \\
\text { Células tumorais } \\
\text { intravasculares }\end{array}$} & Presente & 5 & 100 & 22 & 100 \\
\hline & Ausente & 0 & 0 & 0 & 0 \\
\hline & Presente & 0 & 0 & 6 & 27,27 \\
\hline & Ausente & 5 & 100 & 16 & 72,73 \\
\hline
\end{tabular}

Os melanomas são caracterizados por um crescimento infiltrativo até à hipoderme (Oxenhandler e Hook, 1979; Bundza e Feltmate, 1990; Pestana, 1995; Withrow e Vail, 2007), característica evidenciada nos melanomas do presente estudo (100\%). Segundo Pestana (1995) e Goldschmidt e Hendrick (2002), os melanomas apresentam um grau variável de pleomorfismo celular e nuclear em que as células possuem grandes núcleos e nucléolos evidentes e as mitoses são mais frequentes. Neste estudo, verificou-se que todos os melanocitomas $(\mathrm{n}=5 ; 100 \%)$ apresentavam uma atipia citonuclear de grau 1 (leve). Já os melanomas apresentavam majoritariamente $(68,18 \%)$ uma atipia citonuclear de grau 3 (severo), seguida de uma atipia citonuclear de grau 2 (moderado) $(31,82 \%)$.

Seguem-se imagens macroscópicas e microscópicas de melanoses, melanocitomas e melanomas (1-6). 


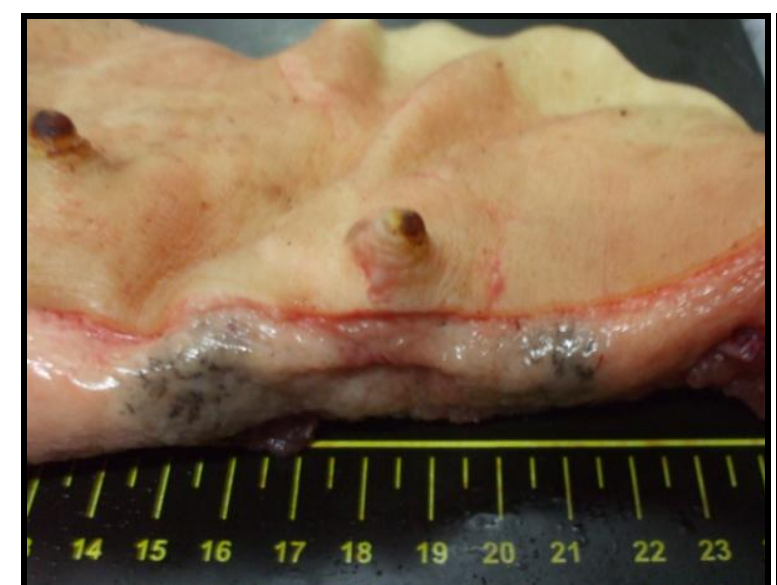

Figura 1. Melanose na glândula mamária (Foto original).

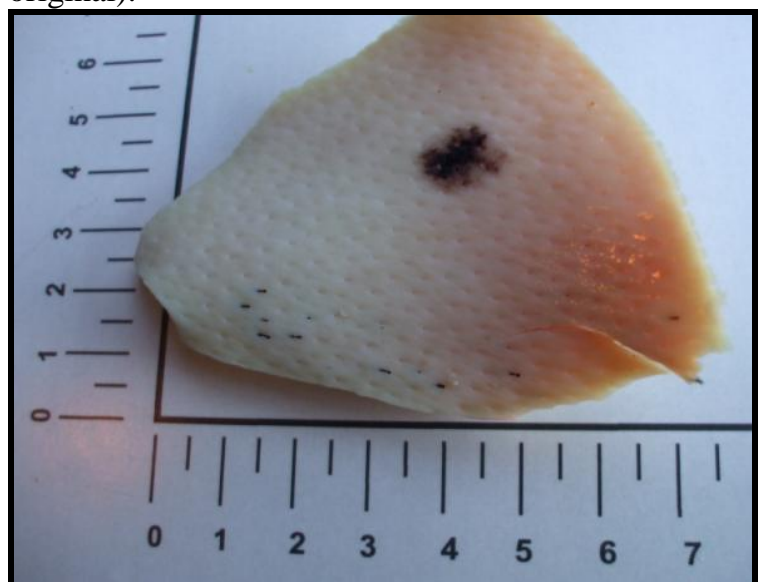

Figura 3. Melanocitoma. Lesão plana negra, de bordas irregulares (Foto original).

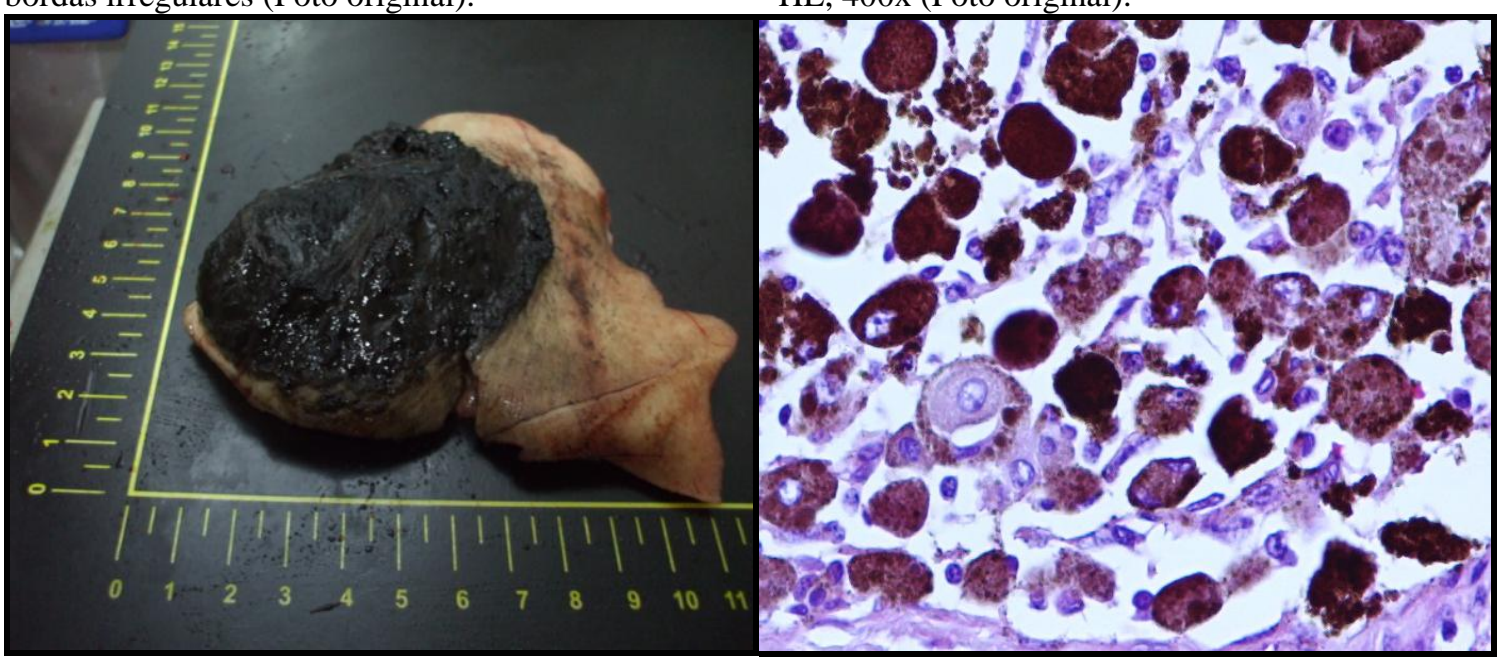

Figura 5. Melanoma cutâneo de tamanho superior a $7 \mathrm{~cm}$, extensamente ulcerado (Foto original).

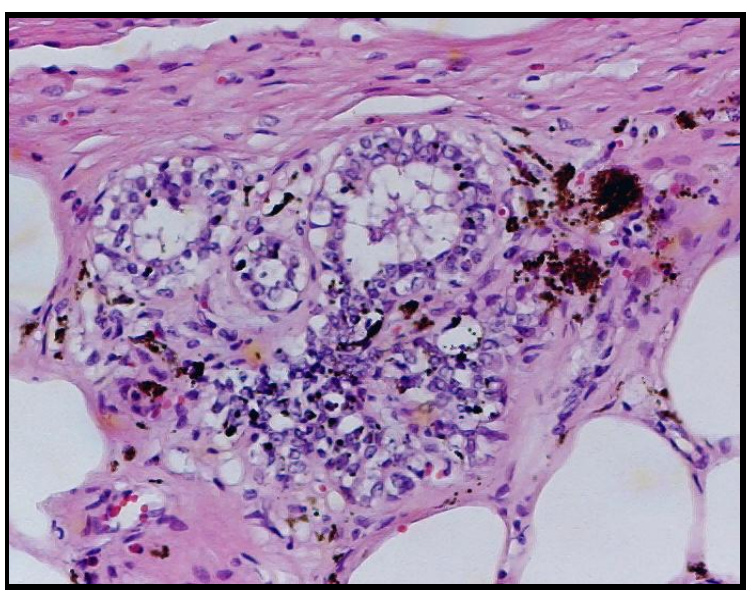

Figura 2. Melanose na glândula mamária. HE, 200x (Foto original).

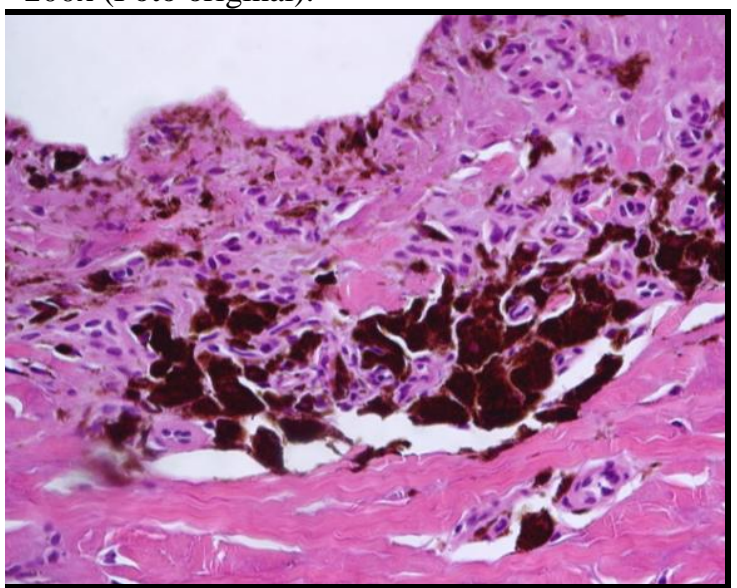

Figura 4. Imagem característica de melanocitoma. HE, 400x (Foto original)

Figura 6. Melanoma. Atipia citonuclear. HE, 400x (Foto original). 


\section{CONCLUSÕES}

$\mathrm{Na}$ inspeção sanitária de suínos podem ser encontradas lesões melanocíticas com características macroscópicas distintas que, no entanto, apresentam um mesmo diagnóstico e lesões semelhantes que podem corresponder a diferentes diagnósticos e, consequentemente, a diferentes decisões sanitárias. Com o presente estudo, foi possível identificar algumas características macroscópicas que podem ser indicadores de lesões melanocíticas, como por exemplo, no caso da melanoase, o aspecto macroscópico semelhante a depósitos cinza nos tecidos e a ausência de ulceração e, no caso do melanoma, a presença de ulceração e a liberação de pigmento negro. Considerando-se o interesse em relação ao assunto no âmbito da inspeção higiênico-sanitária de suínos, assim como a falta de informação científica subjacente ao tema, é fundamental a realização de mais estudos, com um maior número de casos, para que seja possível tirar conclusões mais definitivas sobre a ocorrência e as características das lesões melanocíticas em suínos ao abate.

\section{REFERÊNCIAS}

BABA A.I. Melanic tumors in comparative oncology. Bulletin USAMV-CN, n.64, 2007, p.1-2.

BECKER, D.; MIHM, M.C.; HEWITT, S.M. et al. Markers and tissue resources for melanoma: meeting report. Cancer Res., v.66, p.10652-1057, 2006.

BUNDZA, A.; FELMATE, T.E. Melanocytic cutaneous lesions and melanotic regional lymph nodes in slaughter swine. Can. J. Vet. Res., v.54, p.301-304, 1990.

CAMARGO, L.P.; CONCEIÇÃO, L.G.; COSTA, P.R. Neoplasias melanocíticas cutâneas em cães: estudo retrospectivo de 68 casos (1996-2004). Braz. J. Vet. Res. Anim. Sci., v.45, p.138-152, 2008.

CARLETON, H.M.; DRURY, R.A.B.; WALLIGTON, E.A. Carleton's Histological Technique. 5.ed. Oxford Medical Publications, 1980. p. 273.
FAO/OMS. Codex Alimentarius - Carne y productos carnicos. Volumen 10. 2.ed. Publicado por la Secretaria del Programa Conjunto FAO/OMS sobre Normas Alimentarias. FAO, Roma, 1994, p.159-241.

GINN P.E; MANSELL J.E.K.L., RAKICH P.M., Skin and appendages. In: Jubb, Kennedy, Palmer's, eds. Pathology of domestic animals. $5^{\mathrm{a}}$ ed. Saunders. 2007:599-600,760.

GOLDSCHMIDT, M.H.; DUSTAN， R.W.; STANNARD, A.A. et al. International histological classification of tumors of the skin of domestic animals. In: WHO international classification of tumors of domestic animals. Second series, Volume III. Washington DC: Armed Forces Institute of Pathology, American Registry of Pathology, 1998, p.38-40.

GOLDSCHMIDT, M.H.; HENDRICK, M.J. Tumors of the skin and soft tissues. In: Meuten D. Tumors in domestic animals. 4.ed. Iowa State Press:Blackwell, 2002. p.78-82.

HERENDA, D.; CHAMBERS, P.G., ETTRIQUI, A. et al. Manual on meat inspection for developing countries. FAO Animal Production and Health, Paper 119. Food and Agriculture Organization of the United Nations, Rome, 2000, Disponível em: <http://www.fao.org/docrep/003/t0756e/t0756e0 0.htm>. Acessado em: 24 fev. 2010.

HORDINSKY, M.K.; RUTH, G.; KING, R. Inheritance of melanocytic tumors in Duroc swine. J. Hered., v.76, p.385-386, 1985.

JIN, B.; ZAID, S.Y.; HOLLOWELL, M. et al. A unique case of urinary blader simple melanosis: a case report and review of the literature. Diagn. Pathol., v.4, p.24, 2009.

JONES, T.; HUNT, R. Veterinary Pathology 5.ed., Lea \& Febiger, Philadelphia, p.79-82, 1983.

LANTERI, G.; MARINO, F.; LAGANÀ, G. et al. Acquired melanosis caused by acorn ingestion in the Nero Siciliano pig. Vet. Pathol., v.6, p.329-333, 2009.

MILLANTA, F.; FRATINI, F.; CORAZZA, M. et al. Proliferation activity in oral and cutaneous canine melanocytic tumours: correlation with histological parameters, location, and clinical behavior. Vet. Sci., v.73, p.45-51, 2002. 
OXENHANDLER, R.W.; HOOK Jr., R.R. Malignant melanoma in the Sinclair miniature swine. Am. J. Pathol., v.96, p.707-714, 1979.

PÉREZ, J.; GARCÍA, P.M.; BAUTISTA, M.J. et al. Immunohistochemical characterization of tumor cells and inflammatory infiltrate associated with cutaneous melanocytic tumors of duroc and iberian swine. Vet. Pathol., v.39, p.445-451, 2002.

PESTANA, E.G.C. Patología especial y diagnóstico de las enfermidades de los enimales domésticos. Universidad Autónoma de Baja California, Mexicali, 1995, p.160,166

PIRES, M.A.; TRAVASSOS, F.S.; GÄRTNER, F. Métodos microscópicos em anatomia patológica. Atlas de patologia veterinária. 1.ed. Lisboa, Lidel Edições Técnicas, Lda., 2004. p.155-177.

RAMOS-VARA, J.A.; BEISSENHERZ, M.E.; MILLER, A. et al. Retrospective study of 338 canine oral melanomas with clinical, histologic, and, immunohistochemical review of 129 cases. Vet. Pathol., v.37, p.597-608, 2000.

RAMOS, A.T.; SOUZA, A.B.; NORTE, D.M. et al. Tumores em animais de produção: aspectos comparativos. Cienc. Rural, v.38, p.148-154, 2008 .

Regulamento (CE) n. ${ }^{\circ} 854 / 2004$ do Parlamento Europeu e do Concelho de 29 de Abril de 2004. Jornal Oficial da União Europeia. 2004.
SCOTT, D.W. Color atlas of farm animal dermatology. 1.ed. Iowa, Blackwell Publishing, 2007, p.238.

SMITH, S.H.; GOLDSCHMIDT, M.H.; MCMANUS, P.M. A comparative review of melanocytic neoplasms. Vet. Pathol., v.39, p.651-678, 2002.

SOBESTIANSKY, J.; BARCELLOS, D. Melanoma e Melanose. In: PERESTRELO-VIEIRA, R.; SOBESTIANSKY, J.; BARCELLOS, D. et al. Doenças dos suínos. 2.ed., Lisboa: Publicações Ciência e Vida, 2000. p.321-322.

SPANGLER, W.L.; KASS, P.H. The histologic and epidemiologic bases for prognostic considerations in canine melanocytic neoplasia. Vet. Pathol., v.43, p.136-149, 2006.

STANNARD, A.A.; PULLEY, L.T. Skin and soft tissues. In: Moulton JE. Tumors in domestic animals. 2.ed. California: University of California Press, 1978. p.62-70.

TISSOT, R.G.; BEATTIE, C.W.; AMOSS, M.S. JR. Inheritance of Sinclair swine cutaneous malignant melanoma. Cancer Res., v.47, p.55425545, 1987.

VARGAS J.; Neoplasis melanocíticas en animales domésticos. Ver Med Vet Zoot., 52:6468, 2005.

WITHROW, S.J.; VAIL, D.M. Withrow \& MacEwen's small animal clinical oncology. 4.ed. Saunders, 2007. p.389-392. 